\title{
Experience of final examination for master's degree in optical engineering
}

Tatiana Ivanova, Kseniia Ezhova, Alexey Bakholdin, Nadezhda Tolstoba, Galina Romanova

Tatiana Ivanova, Kseniia Ezhova, Alexey Bakholdin, Nadezhda Tolstoba, Galina Romanova, "Experience of final examination for master's degree in optical engineering," Proc. SPIE 9793, Education and Training in Optics and Photonics: ETOP 2015, 979320 (8 October 2015); doi: 10.1117/12.2223232

SPIE Event: Education and Training in Optics and Photonics: ETOP 2015, 2015, Bordeaux, France 


\title{
Experience of final examination for master's degree in optical engineering
}

Tatiana Ivanova, Kseniia Ezhova, Alexey Bakholdin, Nadezhda Tolstoba, Galina Romanova

ITMO University (Russian Federation)

\begin{abstract}
At the end of master program it is necessary to measure students' knowledge and competences. Master thesis is the one way, but it measure deep knowledge in quite narrow area. Another way of measure is additional final examination that includes topics from the most important courses. In Applied and Computer Optics Department of ITMO University such examination includes theoretical questions and practical tasks from several courses in one examination. Theoretical section of examination is written and second section is practical. Practical section takes place in laboratory with real equipment or with computer simulation. In the paper examples of tasks for master programs, and results of examination are presented.
\end{abstract}

Keywords: final examination, test, knowledge measure, master program

\section{INTRODUCTION}

At the end of master program it is necessary to measure students' knowledge and competences. Master thesis is the one way, but it measures deep knowledge in quite narrow area. Another way of measure is additional final examination that includes topics from the most important courses. Usually final examination is oral. Students give answers to the questions by one or several courses in the curricula. Such examination format is not objective; it takes a lot of time for professors and for students and it does not measure practical ability to use knowledge for real tasks at all. Since 2010 at Applied and Computer Optics Department of ITMO University final examination was changed. Now it includes theoretical written questions and practical tasks from several courses in one examination.

Final examination in this form allows not only objective measure of student knowledge and ability to use it for practical task. It also shows gaps in the knowledge to the lecturer and allows correcting the course in the future. Especially it is interesting to see students' knowledge a few months after taking course.

\section{EXAMINATION PROCEDURE}

Theoretical section of examination is written and includes theoretical questions, exercises and test questions. Second section is practical. Practical section takes place in laboratory with real equipment or with computer simulation. Each task is measure in points, total grade is 100. A contribution of each course determines according to its ECTS in the curricula.

Theoretical part duration is 4 academic hours. Students can use any printed or hand writings sources (books, courses guidelines, lecture notes, solution examples, etc.). Communication is forbidden and using any electronic devises (to avoid communication too). All students have the same set of tasks, but each year the tasks are changed completely. Our experience has shown that even for one set of tasks it is enough two tutors for supervision of 20 students during the exam.

When theoretical part is finished, students go to the computer class or laboratory and have another academic hour for practical task.

One set of tasks makes the exam clearer, when criterion is the same for all students and doesn't depend from tasks variant. Each task measure in points, all points are summarize and it is possible to create distribution (diagram) that shown the exam result.

\section{EXAMINATION TASK EXAMPLE}

In this section we show an example of full examination task for master program "Computer optics". Tasks from several courses include into the task, there are theoretical questions, exercises, tests and one practical task.

Education and Training in Optics and Photonics: ETOP 2015, edited by Eric Cormier, Laurent Sarger Proc. of SPIE Vol. 9793, 979320 - @ 2015 SPIE, IEEE, OSA, ICO · doi: 10.1117/12.2223232 
Table 1. Examination tasks example

\begin{tabular}{|c|c|}
\hline 1. Course "Optical Image Modeling" & $\begin{array}{l}\text { 1.1. Exercise ( } 3 \text { points) } \\
\text { 1.2. Test ( } 3 \text { points) } \\
\text { 1.3. Exercise ( } 3 \text { points) } \\
\text { 1.4. Practical task ( } 20 \text { points) }\end{array}$ \\
\hline 2. Course "Image Processing" & $\begin{array}{l}\text { 2.1. Test ( } 3 \text { points) } \\
\text { 2.2. Test ( } 3 \text { points) } \\
\text { 2.3. Test ( } 3 \text { points }) \\
\text { 2.5. Test ( } 3 \text { points) }\end{array}$ \\
\hline 3. Course "Hologram optics and devices" & $\begin{array}{l}\text { 3.1. Theoretical question ( } 12 \text { points) } \\
\text { 3.2. Theoretical question ( } 12 \text { points) }\end{array}$ \\
\hline 4. Course "Optimization recipes" & $\begin{array}{l}\text { 4.1. Exercise ( } 4 \text { points }) \\
\text { 4.2. Exercise ( } 12 \text { points) }\end{array}$ \\
\hline 5. Course "Testing methods for optical systems" & $\begin{array}{l}\text { 5.1. Theoretical question ( } 4 \text { points) } \\
\text { 5.2. Test ( } 3 \text { points) } \\
\text { 5.3. Exercise ( } 8 \text { points) }\end{array}$ \\
\hline
\end{tabular}

\section{Course "Optical Image Modeling"}

\subsection{Exercise (3 points)}

Which diffraction model you can use in case of beam diameter is $100 \mu \mathrm{m}$, distance is $0.1 \mu \mathrm{m}$, and wavelength is $0.5 \mu \mathrm{m}$.

\subsection{Test (3 points)}

There are several image intensity distributions for various partial coherence factors for the same object. Which of these images is corresponding to incoherent illumination?

a)

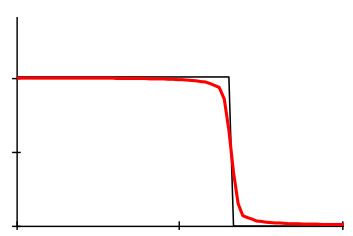

b)

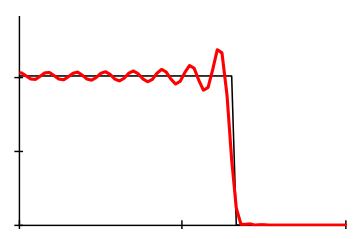

c)

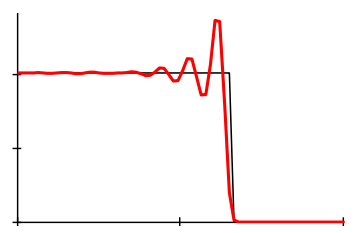

d)

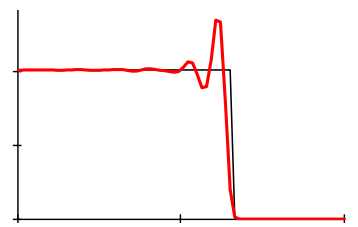

\subsection{Exercise (3 points)}

There are known optical system parameters $(\mathrm{NA}=0.5, \lambda=0.5 \mu \mathrm{m})$, sample size $(200 \times 200)$ and pupil coverage ( 8 canonical units) in optical image modeling. Calculate canonical coordinates step on image and on pupil and size of object in $\mu \mathrm{m}$.

\subsection{Practical task (20 points)}

Develop C++ application determining PSF of an optical system. Parameters of the optical system: round pupil with a central obscuration, free of aberrations, transmission is uniform in the pupil. Use code templates "complex_sample" and "FFT".

Input data: sample size $=256 \times 256$, pupil step $=0.1$. Output data: files with intensity distribution in PSF. 


\section{Course "Image Processing"}

\subsection{Test ( 3 points)}

Which color model is more suitable for color correction?
a) $\mathrm{XYZ}$ or Lab
b) RGB
c) CMYK
d) HSV

\subsection{Test (3 points)}

Which file formats are using compression by LZW method?

\subsubsection{Test (3 points)}

Choose mask image filtering methods:
a) Wiener filter
b) Prewitt filter
c) Laplace filter
d) Median filter
e) Sobel filter

\subsection{Test ( 3 points)}

Make sequence coding by RLE method. The initial sequence is: 1,2,3,4,4,4,4,2,4.

\subsection{Test (3 points)}

Modulation transfer function is:
a) module of point spread function
b) module of contrast transfer function
c) module of optical transfer function
d) phase of complex amplitude

\section{Course "Hologram optics and devices"}

\subsection{Theoretical question (12 points)}

What is influence to the incident wave angle in hologram registration? Describe it influence to the restored image.

\subsection{Theoretical question (12 points)}

In what areas using of thin and volumetric holographic optical elements is more effective? In what reason?

\section{Course "Optimization recipes"}

\subsection{Exercise (4 points)}

Find extremum of function $\varphi\left(x_{1}, x_{2}\right)=\left(x_{1}-4\right)^{2}+\left(x_{2}-4\right)^{2}$ and define its kind (local minimum, local maximum or saddle point).

\subsection{Exercise (12 points)}

Find at least one stationary point (6 points) and Hessian matrix in this point (6 points) for function $\varphi(x, y)=-7 y^{2}+x^{12} y-6 y^{2} x-2$. 


\section{Course "Testing methods for optical systems"}

\subsection{Theoretical question ( 4 points)}

What type of interferometer is shown on the picture? What kind of surface can be controlled by it?

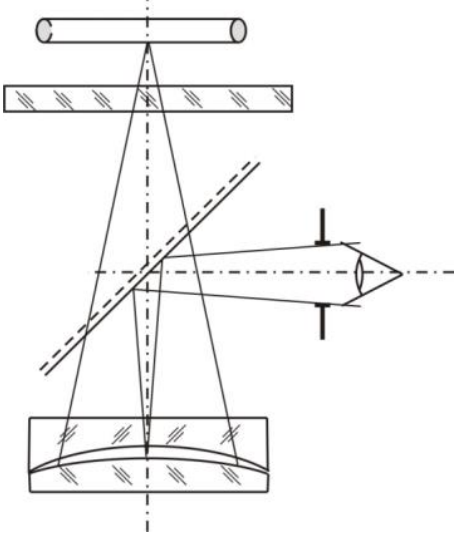

\subsection{Test ( 3 points)}

There are fringe patterns that was obtained by Fizeau interferometer (reference wave front is flat). There is only one 3order aberration is in the system, all others are negligible quantity. Which kind of 3-order aberration is in the optical system?

a)

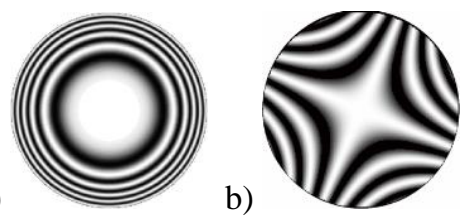

\subsection{Exercise (8 points)}

During fringe pattern processing was defined Zernike coefficients: $C_{60}=0.1 \lambda, C_{11}=-0.5 \lambda$, all others coefficients are negligible quantity. What kind of aberrations are in the optical system ( 2 points)? Calculate wave aberration in meridianal cross section on the pupil edge ( 2 points). Calculate RMS error of wave front ( 2 points) and draw wave aberration graph (2 points).

\section{EXAMINATION RESULT EXAMPLE}

After the examination it is useful to see distribution of point by students. The figure 1 is shown distribution of total point by students for 2013 year. It is clear that most of students are in the middle of range that means the task is relevant.

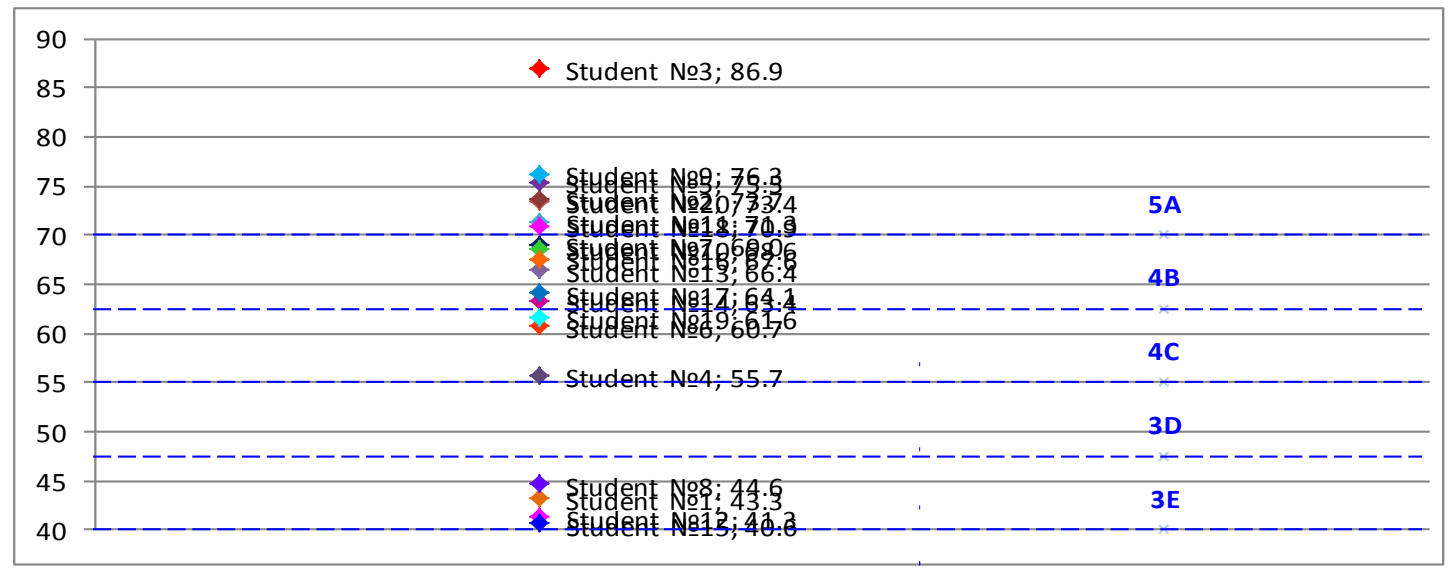

Figure 1. Final examination result (2013 year) 
On the next figure distribution of total points by each task is shown. The practical task marked with red. It is clear that practical task one of the most difficult task of all, and unfortunately it is shown that practical usage of knowledge more difficult for students than theoretical questions. Also on this figure clear that some of tasks too easy, and some of them are too difficult. It is not bad, difficult task makes difference between student (and they total grade) more clear. Easy tasks give to all student chance to pass examination. Certainly it gives a hint what part of our courses is needed to be taught harder.

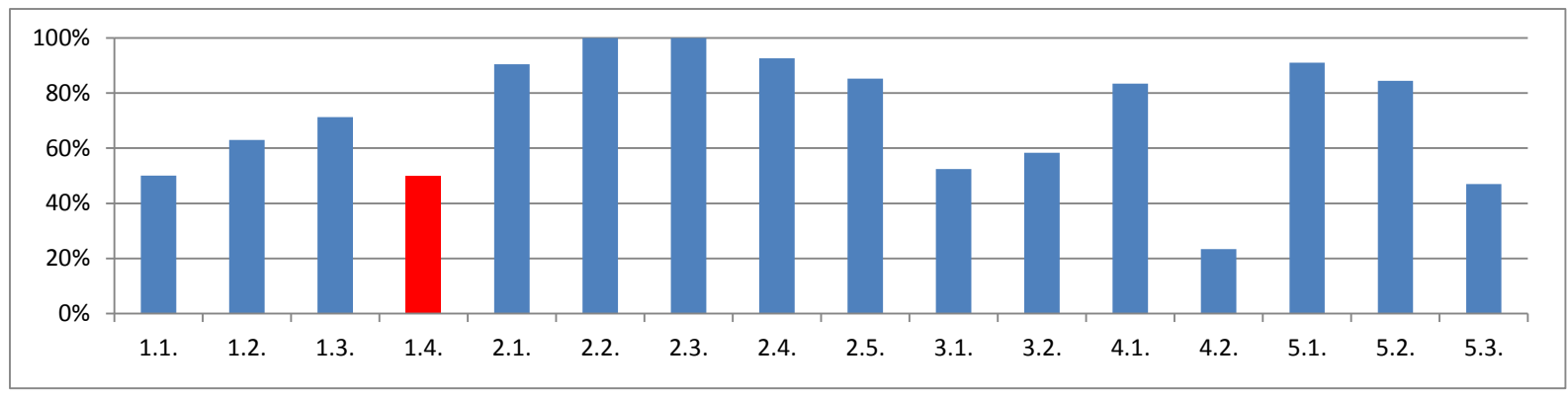

Figure 2. Statistical distribution by tasks

\section{CONCLUSIONS}

Thus, final examination can measure students' knowledge and their ability to use it for practical task. One set of tasks and measure each task in point can make final mark more impartial. Also it shows gaps in the knowledge to the lecturer and allows correcting the course in the future. Analysis of examination result shows that exactly practical part of examination is more difficult for students and it is necessary to improve using practical experience during education. 